\title{
Three-Dimensional Organization of the Recurrent Axon Collateral Network of the Substantia Nigra Pars Reticulata Neurons in the Rat
}

\author{
Philippe Mailly, ${ }^{1}$ Stéphane Charpier, ${ }^{2}$ Annie Menetrey, ${ }^{2}$ and Jean-Michel Deniau ${ }^{2}$ \\ ${ }^{1}$ Neurobiologie des Signaux Intercellulaires, Centre National de la Recherche Scientifique, Université Pierre et Marie Curie, 75005 Paris, France, and \\ ${ }^{2}$ Institut National de la Santé et de la Recherche Médicale, Unité 114, Chaire de Neuropharmacologie, Collège de France, 75231 Paris, France
}

\begin{abstract}
The substantia nigra pars reticulata (SNR) constitutes a major output nucleus of the basal ganglia where the final stage of information processing within this system takes place. In this study, using juxtacellular labeling and three-dimensional reconstruction methods, we investigated the spatial organization of the intranigral innervation provided by single GABAergic projection neurons from the sensorymotor subdivision of the rat SNR. Confirming previous observations, most labeled SNR cells were found to possess a local axonal network innervating the pars reticulata and pars compacta (SNC). Within the SNR, axons of these cells were distributed along curved laminas enveloping a dorsolaterally located core, thus mostly respecting the onion-like compartmentalization of this nucleus. Although the axonal projection field mostly remained confined to the dendritic field of the parent neuron, it usually extended beyond its limits in caudal, lateral, and/or dorsal directions. Because SNR cells are GABAergic, this pattern of axonal projection suggests the existence of lateral inhibitory interactions between neurons belonging to the same as well as to adjacent functional subdivisions. Axonal projections of SNR cells to the SNC formed longitudinal bands. These bands partly occupied the SNC region projecting to the striatal sector from which parent SNR cells receive their afferents. These data indicate that SNR cells contribute to an indirect nigrostriatal loop circuit through which the striatum could upregulate its level of dopaminergic transmission via a disinhibition of nigrostriatal neurons. Spatial relationships between elements of this indirect nigrostriatonigral circuit indicate that this circuit operates in both a closed and open loop manner.
\end{abstract}

Key words: basal ganglia; juxtacellular labeling; parallel processing; nigrostriatal loop; substantia nigra pars compacta; threedimensional reconstructions

\section{Introduction}

The pars reticulata of the substantia nigra (SNR), which is a main output nucleus of the basal ganglia, conveys the striatal outflow to brainstem premotor networks and thalamic nuclei related to motor, premotor, prefrontal, and associative sensory cortical areas (Deniau and Chevalier, 1992; Middleton and Strick, 1996, 2002; Sakai et al., 1998) (for review, see also Alexander et al., 1986; Parent, 1990; Deniau and Thierry, 1997; Bolam et al., 2000). Because of the massive reduction in the number of neurons between the striatum and the SNR and in consideration of the large dimension of the dendrites of SNR cells, the convergent nature of the striatonigral network has long been emphasized (Percheron and Filion, 1991). However, increasing evidence indicates that basal ganglia output nuclei mostly preserve in their outflow the specificity of their striatal inputs (Alexander and Crutcher, 1990; Deniau and Thierry, 1997; Groenewegen et al., 1999). Indeed, as documented in the rat SNR, projections from all of the striatal functional subterritories (defined by their specific cortical affer-

Received Feb. 14, 2003; revised March 28, 2003; accepted March 31, 2003.

This work was supported by Fondation de France Grant 20020111943. We thank J. Glowinski and A. M. Thierry for their critical reading of this manuscript.

Correspondence should be addressed to Dr. Jean-Michel Deniau, Institut National de la Santé et de la Recherche Médicale, Unité 114, Chaire de Neuropharmacologie, Collège de France, 11 Place Marcelin Berthelot, 75231 Paris Cedex 05, France. E-mail: jean-michel.deniau@college-de-france.fr.

Copyright $\odot 2003$ Society for Neuroscience $\quad$ 0270-6474/03/235247-11\$15.00/0 ents) and the somata of the different subpopulations of nigral neurons are precisely ordered along a series of longitudinal laminas arranged in an onion-like manner (Deniau and Chevalier, 1992; Mailly et al., 2001). These laminas envelop a central core located dorsolaterally in the SNR. This remarkable architecture, which favors the formation of input-output registers between particular striatal subterritories and specific subpopulations of nigral output neurons, strongly suggests that basal ganglia comprise a series of channels characterized by distinct input-output relationships.

In addition to innervating structures extrinsic to the basal ganglia, the projection neurons of SNR provide a local axon collateral network that innervates both the SNR and the substantia nigra pars compacta (SNC) (Juraska et al., 1977; Karabelas and Purpura, 1980; Grofova et al., 1982). Because of the GABAergic nature of SNR cells, this local circuit is responsible for inhibitory interactions between nigral cells (Deniau et al., 1982; Tepper et al., 1995). However, its functional organization remains obscure. In particular, it remains to be determined whether this local inhibitory circuit either supports interactions between neurons related to the same striatal functional sector, and therefore participates in information processing within striatonigral channels, or contributes to neuronal interactions between distinct channels.

This study was undertaken to analyze the three-dimensional (3D) organization of the intranigral axonal arborizations from single GABAergic projection neurons of the SNR. For this pur- 
pose, cells from previously identified subdivisions of the lateral sensory-motor region of the SNR (Deniau et al., 1996) were electrophysiologically characterized by their spontaneous discharge, spike duration, and response to cortical stimulation, and then labeled using juxtacellular injection of Neurobiotin (Pinault, 1996). Spatial relationships between local axonal projection and dendritic fields of parent neurons were then examined on 3D reconstructed models of the labeled neurons. In addition, axonal projections to the SNC were mapped and compared with the topographical distribution of nigrostriatal neurons. Some of the SNR neurons used in this analysis were taken from a sample of cells whose dendritic morphology was described previously (Mailly et al., 2001).

\section{Materials and Methods \\ Animal preparation}

Experiments were performed in 52 adult male Sprague Dawley rats (weight, 250-350 gm; Charles River, St Aubin les Elbeuf, France). Surgical procedures were applied in strict accordance with the European Communities Council Directive 86/609/EEC (1986). Animals were initially anesthetized by an injection of pentobarbital (40 mg/kg, i.p.; Sanofi, Libourne, France) and fixed in a conventional stereotaxic apparatus (Unimécanique, Epinay sur Seine, France). Anesthesia was maintained throughout the experiment by additional doses of pentobarbital $(20 \mathrm{mg} /$ $\mathrm{kg}$, i.p.) or ketamine (50 mg/kg, i.m.; Imalgène 500, Rhone-Mérieux, France). Incision and pressure points were infiltrated with lidocaine. Heart beat and pedal withdrawal reflex were monitored during the experiment to assess the depth of anesthesia. Body temperature was maintained between 37 and $38^{\circ} \mathrm{C}$ using a homeothermic blanket.

\section{Electrophysiological characterization of nigral neurons}

Extracellular single-unit recordings in the SNR were made using glass pipettes (15-20 M $\Omega$ ) containing $1.5 \%$ Neurobiotin (Vector Laboratories, Burlingame, CA) in $0.5 \mathrm{M} \mathrm{NaCl}$. Single neuron action potentials were recorded using the active bridge mode of an Axoclamp 2B amplifier (Axon Instruments, Foster City, CA), amplified $(1000 \times)$ and filtered $(0.3-3 \mathrm{kHz})$ with an $\mathrm{AC} / \mathrm{DC}$ amplifier (DAM-50; World Precision Instruments, Hertfordshire, UK). SNR GABAergic neurons were distinguished from nigral dopaminergic neurons by their classical electrophysiological characteristics: short duration spikes (total duration, $<2 \mathrm{msec}$ ) and ability to generate highfrequency action potential discharges $(>10 \mathrm{~Hz})$ without a decrease in spike amplitude (Bunney et al., 1973; Deniau et al., 1978; Guyenet and Aghajanian, 1978). During the experiments, the electrical activity of SNR cells was examined online on a memory oscilloscope (Tektronix, Courtaboeuf, France) and stored with a digital tape recorder (DTR-1404; Biologic, Claix, France) for off-line analysis. Spikes were detected from instrumental noise using a window discriminator (World Precision Instruments) and sampled by a computer connected to a laboratory interface (CED 1401Plus; Cambridge Electronic Design, Cambridge, UK).

To label nigral neurons within the projection fields from the different functional sectors of the striatal sensory-motor area, electrophysiological responses of SNR cells evoked by electrical stimulation of various sensory-motor corti$\mathrm{cal}$ areas were used as a guide for stereotaxic placement of recordings within the SNR (stereotaxic coordinates: anterior, 3-4; lateral, 2-3). Stimuli (200 $\mu$ sec duration; $20-100 \mu \mathrm{A}$ intensity) were applied to either the orofacial motor cortex (anterior, 12-11.5; lateral, 4.5-4; depth, $1.5 \mathrm{~mm}$ under surface), the foreleg motor cortex (anterior, 11.2; lateral, 3.4; depth, $1.5 \mathrm{~mm}$ under surface), the oculomotor area (anterior, 11.7; lateral, 1.5; depth, $1.5 \mathrm{~mm}$ under surface), or the prelimbic area of the prefrontal cortex (anterior, 11.2; lateral, 0.7 ; depth, $3 \mathrm{~mm}$ under surface) ipsilateral to the recorded SNR cells. Stereotaxic coordinates of recording and stimulating sites were determined using the atlas of Paxinos and Watson (1986) and the functional map of the sensory-motor cortex established by Neafsey et al. (1986). Electrical stimulation of the motor cortex was achieved through a bipolar stimulating electrode ( $1 \mathrm{~mm}$ tip separation) inserted orthogonal to the cortical surface at a depth of $1.5 \mathrm{~mm}$. The prelimbic cortex was stimulated using a coaxial stainless-steel electrode (diameter, $400 \mu \mathrm{m}$; tipbarrel distance, $300 \mu \mathrm{m}$ ). As classically established (Ryan and Clark, 1991; Kita, 1994; Maurice et al., 1999), cortical stimulation evokes three main types of events in SNR cells: a short latency excitation resulting from the activation of the fast corticosubthalamonigral circuit, an inhibition of longer latency caused by the activation of the corticostriatonigral circuit, and a late excitation triggered by the activation of the polysynaptic corticostriatopallidosubthalamonigral circuit.

\section{Labeling and visualization of nigral neurons}

Recorded neurons were labeled using juxtacellular injection of Neurobiotin (Pinault, 1996). Briefly, positive pulses of current (1-8 nA; $200 \mathrm{msec}$ duration) were applied at a frequency of $2.5 \mathrm{~Hz}$ through the bridge circuit of the amplifier. The current was slowly increased, and the electrode was advanced by steps of $1 \mu \mathrm{m}$ (LSS-1000 Inchworm Motor Positioning System; Burleigh Instruments, Fishers, NY) onto the neuron until the injected current drove the cell discharge. Current pulses were applied for a 10-30 min period to obtain reliable labeling of neuronal processes.

Two to $5 \mathrm{hr}$ after the end of the injection, the animal received a lethal dose of pentobarbital and was perfused via the ascending aorta with 200 $\mathrm{ml}$ of saline followed by $500 \mathrm{ml}$ of a solution containing $0.3 \%$ glutaral-

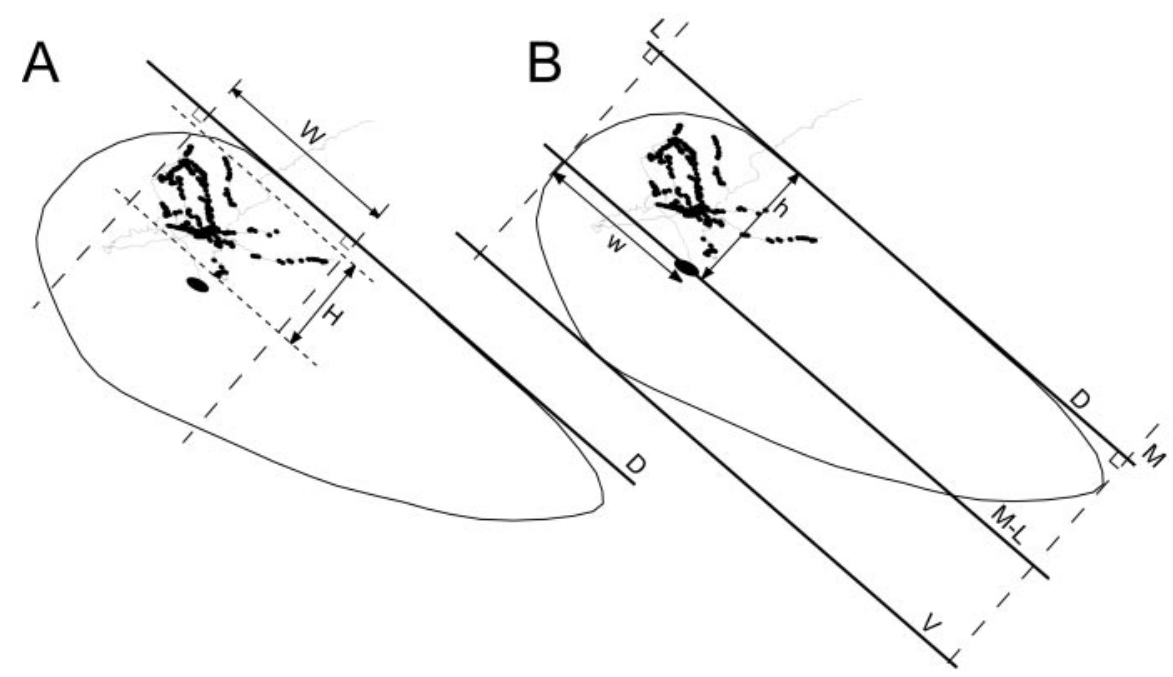

Figure 1. Coronal sections of the left SNR illustrating the reference axis used to determine the coordinates of the somata of the labeled neurons within the SNR and to measure the length of axonal terminal fields. $A$, The mediolateral ( $W$ ) extent and dorsoventral $(H)$ extent of terminal fields were (indicated by dashed lines) measured relative to the $D$-axis passing along the dorsal edge of the SNR. This axis takes into account the slope of the mediolateral axis of the SNR into the brain and allows definition of the largest mediolateral axis of the SNR. $B$, Dorsoventral and mediolateral coordinates of the neuronal somata within the SNR were determined using the $D-, M-L-$, and $V$-axes. These axes were traced on the coronal section of the SNR that contains the soma of the neuron studied. The $D$-axis passes along the dorsal surface of the SNR and defines the mediolateral axis of the SNR. The $M$ - $L$-axis parallels the $D$-axis and passes through the soma of the neuron. The $V$-axis parallels the $D$-axis and passes tangentially to the ventral surface of the SNR. The $M$ - and $L$-axes are orthogonal to the $D$-axis and pass tangentially to the medial and lateral edge of the SNR, respectively. The dorsoventral coordinate of the neuron $(h)$ was determined by measuring the distance between the $M$ - $L$ - and $D$-axes. To compare the position of neurons from different animals, this value was normalized relative to the maximal thickness of the SNR measured as the distance between the $D$ - and $V$-axes. The mediolateral coordinate $(w)$ was determined by measuring the distance between the soma of the neuron and the $L$-axis. This measure was normalized relative to the maximal extension of the nucleus along its mediolateral axis. This extension was determined as the distance separating the $L$ - and $M$-axes. 
Table 1. Position of the soma of the neurons labeled in the various sensorimotor subdivisions of the SNR (nigral lamina), reference number (\#), and extension and distribution of the axonal projections within the SNR and the SNC

\begin{tabular}{|c|c|c|c|c|c|c|c|c|c|c|c|c|c|c|}
\hline \multirow[b]{3}{*}{ Nigral lamina } & \multirow[b]{3}{*}{$\#$} & \multicolumn{8}{|c|}{ Axonal projections in SNR } & \multicolumn{5}{|c|}{ Axonal projections in SNC } \\
\hline & & \multirow{2}{*}{$\begin{array}{l}\text { First } \\
\text { branch }\end{array}$} & \multicolumn{2}{|l|}{$\mathrm{R}-\mathrm{C}$} & \multicolumn{2}{|l|}{$M-L$} & \multicolumn{2}{|l|}{ D-V } & \multirow[b]{2}{*}{ Boutons } & \multicolumn{2}{|l|}{$\mathrm{R}-\mathrm{C}$} & \multicolumn{2}{|l|}{$M-L$} & \multirow[b]{2}{*}{ Boutons } \\
\hline & & & $\mu \mathrm{m}$ & $\%$ & $\mu \mathrm{m}$ & $\%$ & $\mu \mathrm{m}$ & $\%$ & & $\mu \mathrm{m}$ & $\%$ & $\mu \mathrm{m}$ & $\%$ & \\
\hline$d l$ & 4 & 544 & 1221 & $80(-)$ & 514 & 100 & 247 & 100 & 110 & 340 & $0(-)$ & 400 & 100 & 85 \\
\hline \multirow[t]{2}{*}{ dll } & $8 \mathrm{~g}$ & 235 & 925 & $65(-)$ & 650 & $74(-)$ & 450 & 100 & 417 & 505 & 100 & 714 & $75(+)$ & 170 \\
\hline & $35 \mathrm{~g} 2$ & 77 & 191 & 100 & 565 & $64(-)$ & 466 & $95(+)$ & 5 & 103 & 100 & 150 & 100 & 19 \\
\hline \multirow[t]{6}{*}{ cc } & 6 & 411 & 522 & $26(-)$ & 298 & 100 & 313 & $98(+)$ & 211 & 250 & $0(-)$ & 275 & 100 & 51 \\
\hline & $8 d$ & 547 & 690 & 100 & 309 & 100 & 181 & 100 & 61 & 400 & $0(-)$ & 145 & 100 & 30 \\
\hline & $11 \mathrm{~d}$ & & & & & & & & 0 & & & & & 0 \\
\hline & $13 \mathrm{~g}$ & 280 & 432 & $90(-)$ & 298 & $95(+)$ & 223 & $0(+)$ & 252 & 300 & 100 & 420 & $34(+)$ & 49 \\
\hline & 28 & 388 & 74 & 100 & 65 & 100 & 75 & 100 & 12 & 629 & $0(-)$ & 172 & 100 & 47 \\
\hline & $35 g 1$ & & & & & & & & 0 & 54 & 100 & 52 & 100 & 5 \\
\hline \multirow[t]{9}{*}{ pl facial } & $5 d$ & 390 & 120 & $0(-)$ & 243 & 100 & 50 & 100 & 5 & 1240 & $70(-+)$ & 1220 & $44(+)$ & 225 \\
\hline & 9 & 277 & 975 & $53(+)$ & 609 & $85(+)$ & 365 & 100 & 164 & 700 & $0(-)$ & 495 & $0(-)$ & 65 \\
\hline & $13 d$ & 498 & 243 & 100 & 500 & 100 & 621 & 100 & 93 & 900 & 100 & 720 & $50(-)$ & 63 \\
\hline & $15 g$ & 243 & 190 & 100 & 182 & 100 & 121 & 100 & 59 & 120 & $0(-)$ & 103 & 100 & 11 \\
\hline & $24 d$ & 168 & 544 & 100 & 555 & $78(-)$ & 220 & 100 & 53 & 172 & $0(-)$ & 69 & 100 & 43 \\
\hline & $24 g$ & 350 & 212 & 100 & 275 & 100 & 225 & 100 & 45 & & & & & 0 \\
\hline & 26 & 607 & 620 & $50(-)$ & 370 & 100 & 400 & $10(+)$ & 105 & 437 & 100 & 166 & 100 & 51 \\
\hline & 27 & 52 & 660 & 100 & 220 & 100 & 407 & 100 & 145 & 1320 & $30(-)$ & 770 & 100 & 282 \\
\hline & 30 & 176 & 344 & 100 & 584 & 100 & 160 & 100 & 87 & & & & & 0 \\
\hline \multirow[t]{4}{*}{ pl limb } & 18 & 21 & 178 & 100 & 222 & 100 & 133 & 100 & 54 & 130 & $0(-)$ & 217 & 100 & 16 \\
\hline & 19 & 247 & 396 & $20(-)$ & 1440 & $20(+)$ & 570 & 50 & 2 & & & & & 0 \\
\hline & 20 & 421 & 1300 & $80(+)$ & 954 & $38(+)$ & 350 & 100 & 256 & 1620 & $75(-)$ & 1260 & $37(+)$ & 303 \\
\hline & 50 & 164 & 500 & $95(+)$ & 468 & 100 & 156 & 100 & 45 & & & & & 0 \\
\hline \multirow[t]{3}{*}{ pl oculomotor } & 10 & 347 & 787 & $90(+)$ & 378 & 100 & 262 & 100 & 175 & 1900 & $70(-+)$ & 675 & 100 & 439 \\
\hline & 21 & 1175 & 903 & $80(+)$ & 260 & $0(+)$ & 315 & 100 & 14 & 166 & 100 & 118 & $0(+)$ & 29 \\
\hline & $22 g$ & 956 & 280 & $0(-)$ & 120 & $0(+)$ & 100 & 100 & 14 & & & & & 0 \\
\hline \multirow[t]{4}{*}{ \| } & 23 & 204 & 90 & 100 & 135 & 100 & 108 & 100 & 13 & & & & & 0 \\
\hline & 36 & 372 & 180 & 100 & 160 & 100 & 150 & 100 & 53 & 182 & 100 & 124 & 100 & 26 \\
\hline & $37 n 1$ & 196 & 66 & 100 & 66 & 100 & 60 & $0(+)$ & 3 & 585 & 100 & 153 & $0(-)$ & 3 \\
\hline & $37 n 2$ & 268 & 270 & $90(-)$ & 120 & 100 & 110 & 100 & 18 & 200 & $0(-)$ & 250 & $0(-)$ & 21 \\
\hline \multirow[t]{3}{*}{$\mathrm{vl}$} & $5 \mathrm{~g}$ & 22 & 654 & $70(-)$ & 1309 & 100 & 80 & 100 & 32 & 654 & $70(-)$ & 1309 & $80(+)$ & 157 \\
\hline & $22 d$ & 494 & 550 & 100 & 250 & 100 & 105 & $0(+)$ & 26 & 1700 & $60(-)$ & 1800 & $53(-+)$ & 175 \\
\hline & 34 & 104 & 66 & 100 & 160 & 100 & 124 & 100 & 12 & 76 & 100 & 192 & 100 & 5 \\
\hline
\end{tabular}

Within the SNR, the rostrocaudal (R-C), mediolateral (M-L), and dorsoventral (D-V) columns indicate the extension ( $\mu \mathrm{m})$ of axonal projections and the proportion of the axonal projections located within the dendritic field of the parent neurons (\%) along the rostrocaudal, mediolateral, and dorsoventral axes, respectively.

In the percentage (\%) columns, +, - , and - + indicate the spatial distribution of the axonal projections located outside of the dendritic field. A + along the R-C-, M-L, or D-V-axis indicates that the axonal terminal field occupies a position rostral, lateral, or dorsal to the soma, respectively. Conversely, a - indicates that the axonal terminal field occupies a position caudal, medial, or ventral to the soma, respectively. Finally, a -++ indicates that the axonal projection field spreads on either side of the soma. The column labeled "boutons" indicates the number of terminal boutons observed in the axonal projection field. Within the SNC, the rostrocaudal (R-C) and mediolateral (M-L) columns indicate the extension $(\mu \mathrm{m})$ and the percentage of axonal projections positioned in register with the dendritic field of the parent neurons $(\%)$ along the rostrocaudal and mediolateral axes, respectively. The spatial codes are the same as used for the SNR. The column labeled "boutons" indicates the number of terminal boutons in the axonal projection field. cc, Central core; dl, dorsal lamina; dll, dorsolateral lamina; Il, lateral lamina; pl, pericore lamina; $\mathrm{vl}$, ventral lamina.

dehyde and $4 \%$ paraformaldehyde in phosphate buffer (PB; $0.1 \mathrm{M} ; \mathrm{pH}$ 7.4). Brains were postfixed for $2 \mathrm{hr}$ in the same fixative solution without glutaraldehyde and then immersed in a solution of $20 \%$ sucrose in PB at $4^{\circ} \mathrm{C}$ until sectioned. Before sectioning, brains were cut dorsoventrally at the cerebellum level along a vertical plane tilted $18^{\circ}$ toward the rostral part of the brain. This procedure generates a reliable plane of sections that allows the obtainment of 3D reconstructed models of the substantia nigra (SN) that are comparable from one animal to another. Frozen sections of fixed brains were cut at $50-70 \mu \mathrm{m}$ in the frontal plane and serially collected in $\mathrm{PB}$ (0.1 M; pH 7.4). After several rinses in PB, Neurobiotin was revealed by incubating sections in a solution of $\mathrm{PB}$ containing $0.3 \%$ Triton $\mathrm{X}-100$ and the avidin-biotin peroxidase complex (ABC; Vector Laboratories; $1: 100)$. Incubated sections were washed in PB $(2 \times$ $10 \mathrm{~min}$ ) before immersion in a solution containing $0.05 \%$ of $3,3^{\prime}-$ diaminobenzidine tetrahydrochloride (Sigma, St. Louis, MO), $0.4 \%$ nickel-ammonium sulfate, and $0.0006 \% \mathrm{H}_{2} \mathrm{O}_{2}$. After several washes in $\mathrm{PB}$, sections were mounted on gelatin-coated slides, counterstained with safranine, and dehydrated through alcohol to xylene for lightmicroscopic examination.

\section{Anatomical analysis}

Neuronal reconstruction. Soma, dendrites, and axons of labeled neurons, as well as SNR boundaries, were precisely drawn under $25-63 \times$ oil immersion objectives and plotted in 3D using the video computer Neurolucida system (MicroBrightField). 3D models of neurons were visualized using the Lightwave software (Newtek, San Antonio, TX) according to the method described previously by Mailly et al., (2001). Threedimensional reconstructed models of neurons could be rotated around the $x$-, $y$-, and $z$-axes. In addition, the sources of light and camera could 
be adjusted to enhance the 3D appearance of reconstructed neurons on the two-dimensional pictures of the models.

Topological parameters of dendritic and axonal projection fields. Dimensions of dendritic and axonal projection fields were measured along the rostrocaudal, mediolateral, and dorsoventral axes, using the reference lines illustrated in Figure 1. Axonal projection fields were determined as the SNR area in which axons bore terminal boutons. Measurements along the rostrocaudal axis were made on horizontal views of the $3 \mathrm{D}$ models of reconstructed neurons. Along the mediolateral axis, extensions of axonal and dendritic fields (Fig. $1 \mathrm{~A}, \mathrm{~W}$ ) were determined on coronal views of reconstructed neurons by measuring the distance between the extremities of the neuronal processes along an axis parallel to the dorsal edge of the SNR (Fig. $1 A$, axis D). Finally, dorsoventral extensions of dendritic and axonal projection fields (Fig. $1 \mathrm{~A}, \mathrm{H}$ ) were determined on coronal views of reconstructed neurons along an axis orthogonal to the above-defined mediolateral D axis. In the SNC, because of the flatness of the structure, measurements of axonal projection fields were performed along only the rostrocaudal and mediolateral axes. Shrinkage of the section thickness was measured and corrected. No measurable shrinkage was observed in the plane of the slide.

Three-dimensional composite models incorporating reconstructed SNR cells and nigrostriatal cell populations projecting to particular striatal functional sectors were generated to determine how the axonal projection fields from SNR neurons relate to the topographic organization of nigrostriatal neurons. These composite 3D models were established using data from previous experimental studies in which nigrostriatal neurons were retrogradely labeled after injection of the retrograde axonal tracer wheat germ agglutinin conjugated to horseradish peroxidase into different striatal functional sectors (Deniau et al., 1996; Maurin et al., 1999). To generate these composite models, the position occupied by labeled neurons within the parent SNR was precisely determined (Fig. $1 B)$. This was achieved by measuring the distance separating the soma from the nucleus boundaries along the rostrocaudal, mediolateral $(w)$, and dorsoventral $(h)$ axes. These values, normalized to the size of the parent SNR along the three $x$-, $y$-, and $z$-axes, were used to reposition the neurons within $3 \mathrm{D}$ models of the nigrostriatal cell populations retrogradely labeled from striatal injections of the retrograde tracer. To take into account differences in the size and shape of the SNR from different animals, dendritic lengths of reconstructed neurons were corrected along the $x$-, $y$-, and $z$-axes by a factor corresponding to the ratio of length, along the three axes, of the parent SNR of the labeled neurons and the target SNR in which the neurons were repositioned. Numerical values are given as mean $\pm \mathrm{SD}$.

\section{Results}

Among the population of 52 neurons injected in the lateral SNR, 32 were stained well enough to allow visualization of their axons beyond the limits of the substantia nigra. These projection neurons were distributed throughout the previously identified sensory-motor subdivisions of the rat SNR (Deniau et al., 1996). The reference number of the labeled neurons, their localization within the various subdivisions of the SNR, and the morphometric characteristics of their intranigral axonal arborizations are indicated in Table 1. As a rule, axons emerged from either the soma or a proximal dendrite and followed an initial caudal direction. All of the axons of examined neurons gave off one to four intranigral collaterals arborizing within the pars reticulata and the pars compacta (Fig. 2A,B), except for one cell (11d) whose axon had no recurrent collateral. Boutons from these recurrent collaterals were either en passant or grouped into clusters. Typical examples are illustrated in Figure 2, $C$ and $D$. The distance from the cell body at which the first axon collateral emerged from the main axon was highly variable from one cell to another $(20-1170 \mu \mathrm{m})$. However, in most cases, the first collateral arose within the first $500 \mu \mathrm{m}(330 \pm 47 \mu \mathrm{m})$ of the initial

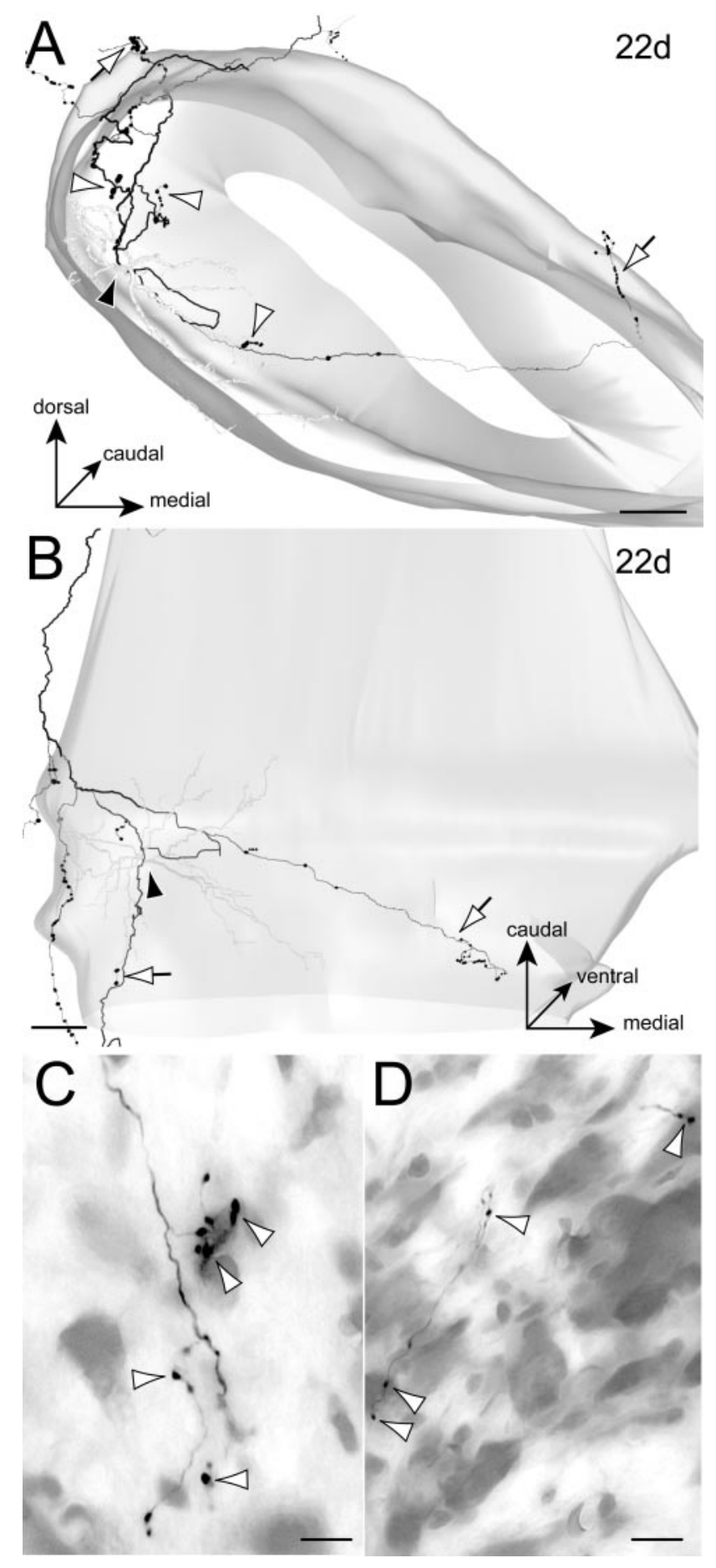

Figure 2. $\quad A, B$, Three-dimensional reconstruction of the neuron 22 d illustrating a typical example of intranuclear axonal arborization provided by a neuron lying in the lateral sensory-motor subdivision of the SNR. The neuron is examined from a rostral view in $A$ and from a dorsal view in $B$. In this and the following figures, the reference number of the neuron is indicated in the top right corner of each panel. Open arrowheads and arrows indicate terminal boutons in the SNR and SNC, respectively. The closed arrowhead points to the soma of the neurons. Note the remarkable pattern of axonal projections directed to the lateral and medial SNC. Scale bars, $150 \mu \mathrm{m}$. C, D, Photomicrographs of terminal axonal boutons (arrowheads) within the SNR ( $C$ and the SNC ( $D$ ). Scale bars, $25 \mu \mathrm{m}$. Note that the innervation of the SNC Occupies the densocellular part.

axonal portion. Although a single axon collateral could innervate both the pars compacta and the pars reticulata, in 26 of the 32 neurons studied, distinct axonal branches innervated these two subdivisions. 


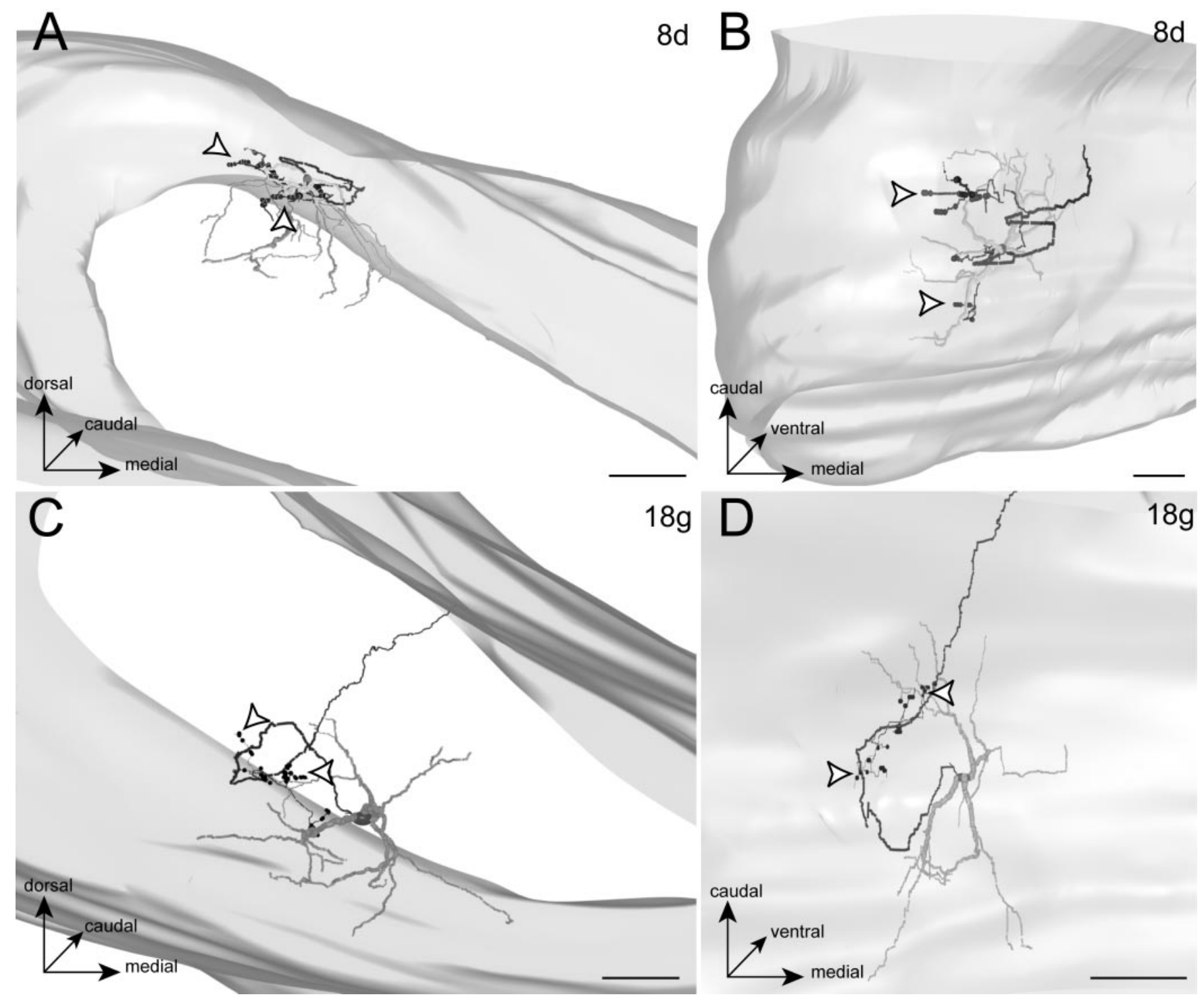

Figure 3. Examples of two neurons ( $8 \mathrm{~d}$ and $18 \mathrm{~g}$ ) whose axonal projections remained within the dendritic field of the parent cell. The 3D models of the reconstructed neurons are shown from a rostral view in $A$ and $C$ and from a dorsal view in $B$ and $D$. Arrowheads point to clusters of terminal axonal boutons. Scale bars, $150 \mu \mathrm{m}$.

\section{Axonal projections within the SNR}

Within the SNR, as reflected by the number and spatial distribution of their terminal boutons, the axonal projection fields varied widely in extent. The number of boutons per cell varied from 3 to 417 (84 \pm 18 boutons), and these boutons were distributed within a spatial domain extending from 66 to $1300 \mu \mathrm{m}$ (460 \pm 7 $\mu \mathrm{m})$ along the rostrocaudal axis, 65 to $954 \mu \mathrm{m}(341 \pm 42 \mu \mathrm{m})$ mediolaterally, and 50 to $621 \mu \mathrm{m}(234 \pm 28 \mu \mathrm{m})$ dorsoventrally. They were scattered within a single extended terminal field or clustered into one to four groups of terminals.

The spatial relationships between the axonal projection field and the dendritic field of parent neurons were examined. Among the 30 investigated neurons, the axonal arborization remained within the dendritic field in 11 cells, projected partly within and partly outside of the dendritic field in 12 cells, and innervated a region located exclusively outside of the dendritic field in 7 cells. As documented in Table 1, the proportion of the axonal projection field remaining within the dendritic field of the parent neuron represented $80 \pm 6 \%$ of its extension along the rostrocaudal axis, $86 \pm 5 \%$ along the mediolateral axis, and $88 \pm 6 \%$ along the dorsoventral axis.
When the axons innervated a domain entirely or partly included within the dendritic field of the parent neuron, the terminal boutons occupied an exocentric position with respect to the parent cell body and with relative consistency in their location (Fig. 3). Indeed, among the 23 studied axons, the terminal boutons were preferentially located dorsally $(n=19)$, laterally $(n=$ $16)$, and caudally $(n=16)$ to the parent cell body (Table 1$)$. In all of these cases, axon terminals were located at a distance from the dendrites of the parent cell, and no evidence of autoptic connections was found.

When axonal projections extended beyond the dendritic field of the parent neuron, in most cases, the long axis of the axonal projection field was oriented rostrocaudally (14 of 19 cells) and paralleled the long axis of the dendritic arborizations. However, this relationship was not exclusive, because in some cases, axonal projections overrun the limits of the dendritic field along the mediolateral $(n=8)$ and/or dorsoventral $(n=7)$ axis. Similarly to the axonal projections located within the dendritic field of the parent cell, those extending beyond its limit presented a preferential distribution with respect to the parent cell body. Indeed, 


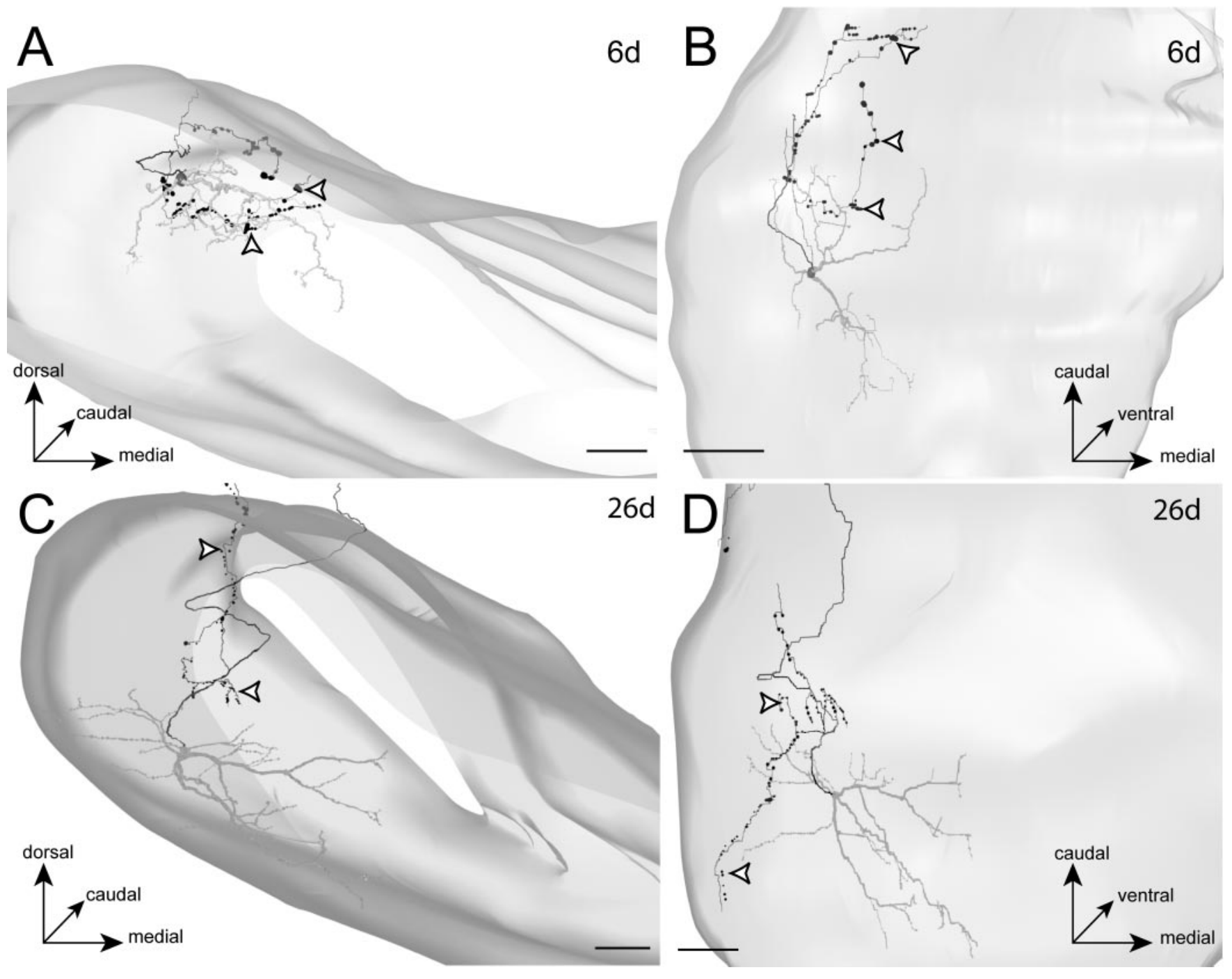

Figure 4. Examples of two neurons ( $6 \mathrm{~d}$ and $26 \mathrm{~d}$ ) with axonal projections located partly outside of the dendritic field. The $3 D$ models of the neurons are examined from a rostral view in $A$ and $C$ and from a dorsal view in $B$ and $D$. Arrowheads indicate clusters of terminal axonal boutons. Scale bars, $350 \mu \mathrm{m}$.

these axonal projections were lying more often caudally $(n=9)$ than rostrally $(n=5)$, were lying laterally $(n=7)$ rather than medially $(n=1)$, and were exclusively located dorsally $(n=7)$. Two representative examples are shown in Figure 4.

We have shown previously that the striatonigral projections and the dendritic arborizations of SNR cells are topographically ordered within the SNR along a series of laminas arranged in an onion-like manner (Deniau et al., 1996, Mailly et al., 2001). Remarkably, recurrent axon collaterals from SNR cells respected this lamellar architecture. As illustrated in Figures 2 and 5, axons followed curved paths enveloping a core region located dorsolaterally in the SNR. This geometrical arrangement has a major functional consequence. Although axonal arborizations extended beyond the dendritic field of the parent cell, they remained mostly within the lamina occupied by the dendritic arborization of their parent neuron. However, as indicated by the thickness of the axonal projection fields and confirmed by the 3D composite models incorporating single SNR cells within the striatal projections, distal portions of axonal projection fields usually spread within adjacent laminas innervated by distinct striatal sectors (Fig. 6).

\section{Axonal projections within the SNC}

The axonal projections of single SNR cells to the SNC varied widely in their number of terminal boutons and their extension. The number of boutons per cell ranged from 3 to 439 (97 \pm 23 boutons). These boutons were distributed within an SNC domain extending rostrocaudally from 54 to $1900 \mu \mathrm{m}(595 \pm 115$ $\mu \mathrm{m})$ and mediolaterally from 52 to $1800 \mu \mathrm{m}(492 \pm 97 \mu \mathrm{m})$. Along the dorsoventral axis, projections of SNR cells were usually limited to the ventral one-half of the SNC. In most cases (20 of 24 neurons), a single SNR cell innervated a restricted segment of the SNC lying in mediolateral register with the dendritic field of the parent neuron (Fig. 7). Such a consistent spatial relationship was not observed along the rostrocaudal axis, and in most cases, axonal projections were located out of register with the dendritic field (Table 1). Indeed, the terminal field occupied an SNC region located caudally to the dendritic field in 12 of the 24 reconstructed axons, whereas it was positioned rostrally in 2 other cases (Fig. 7C,D).

As illustrated in Figures 2, 5, and 6, trajectories taken by axons to reach the SNC strikingly respected the lamellar architecture of the SNR. Whereas axons of neurons located in either the dorsal 

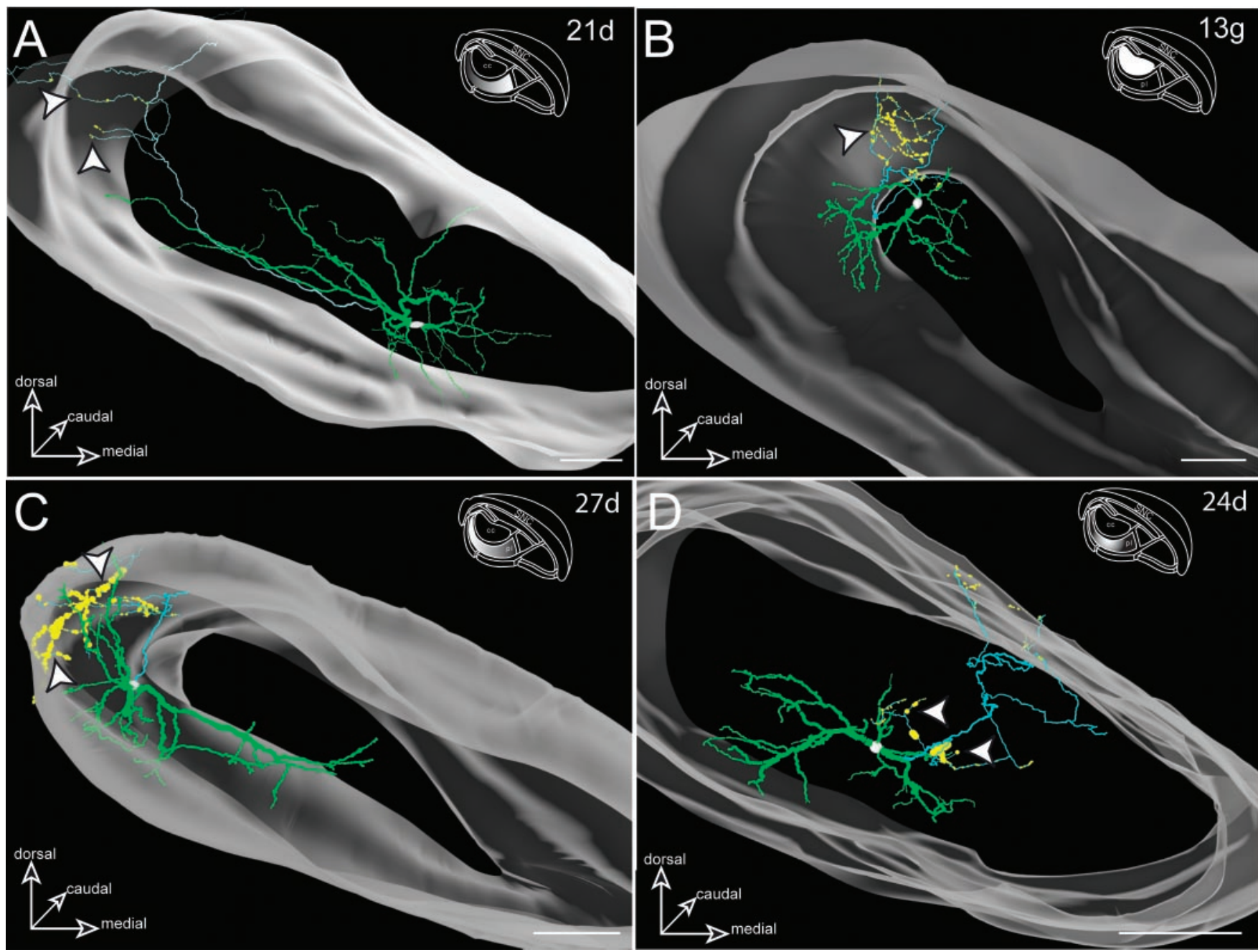

Figure 5. Rostral views of 3D models of neurons $21 \mathrm{~d}(A), 13 \mathrm{~g}(B), 27 \mathrm{~d}(C)$, and $24 \mathrm{~d}(D)$ lying in different regions of the nigral onion-like structure (inset, filled areas), illustrating that the axons conform to the lamellar architecture of the SNR (inset). The soma is represented in white, the dendritic arborization in green, the axon in blue, the axonal terminal boutons in yellow, and the SNR in gray. Arrowheads indicate clusters of terminal boutons. Scale bars, $350 \mu \mathrm{m}$.

lamina or the central core of the nigral onion-like structure followed a rather straight course toward the overlying portion of the SNC, axons of neurons located more ventrally presented curved trajectories enveloping laterally and medially the SNR core region. As a consequence, axons of cells lying ventrally to the core innervated SNC regions located laterally and/or medially to parent cell bodies. Although most of the SNR cells studied obeyed this rule, two neurons located in the most ventral SNR part innervated the SNC via a direct trajectory passing through the central core, orthogonally to the plane of the nigral laminas.

According to previous studies in which retrograde axonal transport was used, nigrostriatal neurons that innervate distinct striatal functional sectors are topographically ordered along the SNC mediolateral axis (Fallon and Moore, 1978; Guyenet and Aghajanian, 1978; Szabó, 1980; Lynd-Balta and Haber, 1994b; Hontanilla et al., 1996; Maurin et al., 1999). As documented in the present study, axons of SNR cells innervated a restricted mediolateral segment of the SNC. Therefore, we have examined how axonal projections of single SNR cells relate to the topographical distribution of the cell bodies of the nigrostriatal neurons within the SNC. For this purpose, composite 3D models of the SN incorporating reconstructed axons of single SNR cells and nigrostriatal cell populations innervating defined functional striatal subterritories were elaborated. As a rule, SNR cells lying in the lamina innervated by a given striatal functional sector preferentially innervated the SNC region projecting back to the striatal sector of origin (Fig. 8). However, as evidenced in Figure 8, axonal projections of a single SNR cell also extended to SNC regions innervating other striatal sectors.

\section{Discussion}

SNR cells interact via recurrent axon collaterals

The SNR constitutes a major output nucleus of the basal ganglia where the final step of information processing within this system takes place (for review, see Parent, 1990; Deniau and Thierry, 1997; Smith et al., 1998; Bolam et al., 2000). Processes through which basal ganglia influence their target structures via the SNR have been partly clarified (Wurtz and Hikosaka, 1986; Chevalier and Deniau, 1990; Fujimoto and Kita, 1992, Mink and Thach, 1993, Kita, 1994; Kitano et al., 1998; Maurice et al., 1999). In their resting state, SNR cells emit a continuous flow of impulses through which they exert a tonic inhibitory influence on their thalamic and brainstem target neurons. This tonic inhibitory influence is modulated in opposite ways by GABAergic afferents from striatum and globus pallidus and glutamatergic afferents from the subthalamic nucleus. Therefore, when the activity of 

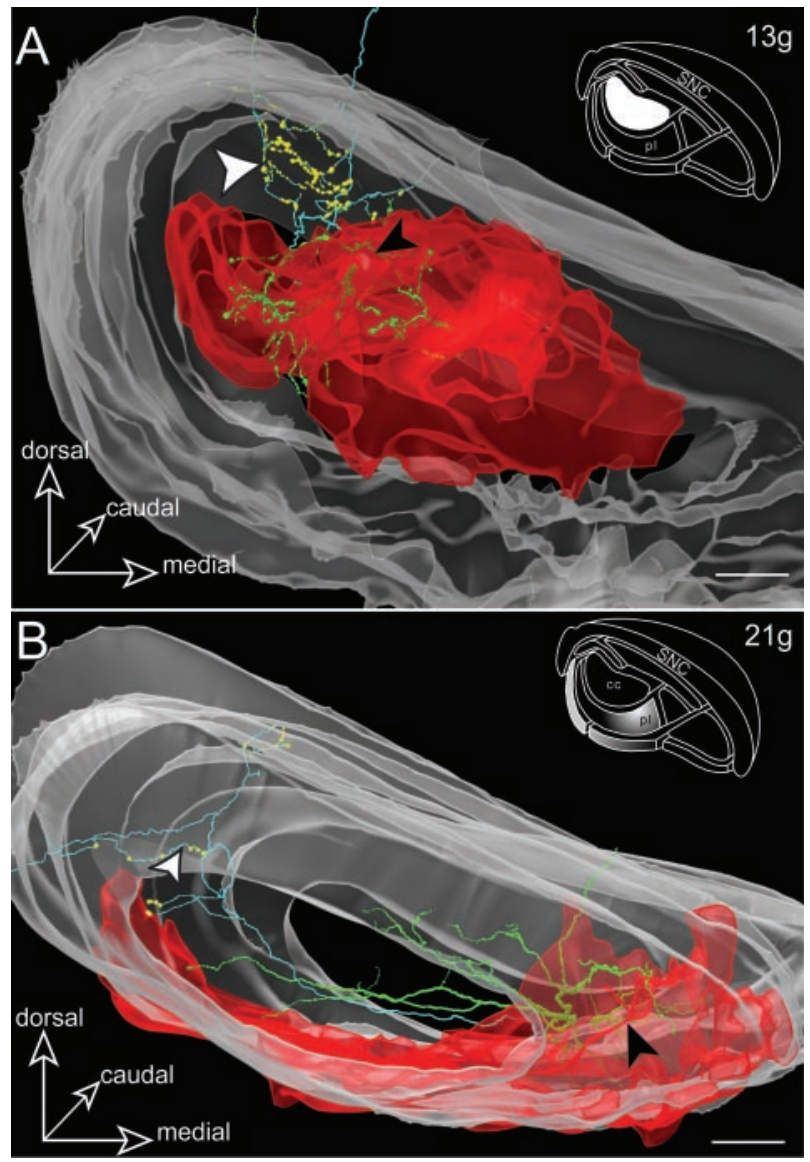

Figure 6. Rostral views of composite 3D models of the SNR incorporating the neurons $13 \mathrm{~g}$ $(A)$ and $21 \mathrm{~g}(B)$ within the projection field of the striatal sectors (inset, filled areas) related to the orofacial sensorimotor and the visuo-oculomotor cortical areas, respectively. The dendritic arborization is represented in green, the axon in blue, the axonal terminal boutons in yellow (arrowhead), the SNR in gray, and the striatal projections in red. Closed arrowheads indicate the soma of the neurons. Opened arrowheads indicate clusters of terminal boutons. Scale bars, $350 \mu \mathrm{m}$.

SNR cells is decreased by their GABAergic inputs, this leads to an increased excitability of their target neurons via a disinhibitory process. Conversely, by increasing the discharge rate of SNR cells, the subthalamic nucleus reinforces the inhibition that basal ganglia exert on their targets.

In addition to their extrinsic sources of inputs, SNR cells are submitted to mutual inhibitory interactions (Deniau et al., 1982; Grofova et al., 1982;). As in anatomical studies reported previously (Juraska et al., 1977; Karabelas and Purpura, 1980; Grofova et al., 1982), the present study also confirms that most GABAergic output neurons from the lateral sensory-motor SNR subdivision emit intranuclear axon collaterals that course for long distances within the nucleus and terminate within and outside the dendritic field of their parent neuron. Among the population of SNR neurons examined, a considerable variability was observed in the extension of the axonal projection fields and the number of terminal boutons. Very likely, such variability did not result from an unreliable labeling of the axons, because in all of the selected cases, axon collaterals and terminal boutons were heavily filled. In addition, axons could be visualized beyond the SNR limits, up to their termination sites in the reticular formation and the superior colliculus, indicating that the animal survival time was long enough to label axons over distances greater than the length of intranigral collaterals. Therefore, this observed heterogeneity likely reflects an actual structural variability in the local axonal network of SNR cells.

The recurrent axon collaterals of SNR cells and the parallel architecture of the basal ganglia

The basal ganglia receive a wide diversity of information originating from the entire cerebral cortex. As originally proposed by Alexander et al. (1986), growing evidence indicates that cortical information that is transmitted to the basal ganglia via the corticostriatal pathway is processed into segregated circuits. Supporting this view, cortical projections originating from functionally distinct areas have been shown to terminate in different striatal subterritories (Webster, 1961; Yeterian and Van Hoesen, 1978, Veening et al., 1980; McGeorge and Faull, 1989; Alexander and Crutcher, 1990; Berendse et al., 1992; Kincaid and Wilson, 1996; Deniau and Thierry, 1997; Brown et al., 1998). Moreover, as recently documented in the rat, because of the remarkable onionlike architecture of the SNR, the segregation of corticostriatal information is mostly maintained in the efferent pathways of the SNR (Deniau and Chevalier, 1992; Deniau et al., 1996; Mailly et al., 2001). Indeed, projections from distinct striatal subterritories and dendritic arborizations of nigral cells are topographically ordered along longitudinal and curved laminas enveloping a dorsolateral core.

Extending our knowledge of the functional organization of the SNR, the present study provides the first description of the 3D organization of the intranigral axon collateral network of the GABAergic output neurons from the lateral sensory-motor subdivision of the rat SNR. The data show that the local axonal network of SNR cells conforms to the onion-like architecture of the nucleus. Thus, when examined from a coronal view, axons of SNR cells were seen to follow curved trajectories enveloping a dorsolateral core region. As a major consequence of this anatomical arrangement, terminal fields of recurrent axon collaterals from SNR cells remained confined within a circumscribed SNR domain including the lamina to which the parent neuron and adjacent laminas belong. These observations suggest that the intranuclear axonal network of SNR cells primarily supports interactions between neurons that share inputs from the same functional striatal sectors rather than between neurons of functionally distinct striatonigral channels. Consistent with this interpretation, axons from neurons in the sensory-motor subdivision of the SNR remained within this functional subdivision and avoided the medial subdivision innervated by the striatal sectors related to prefrontocortical/limbic cortical areas.

\section{What is the functional role of the neuronal interactions supported by the local axonal network of SNR cells?}

As an output nucleus of the basal ganglia, the SNR plays a major role in the expression of striatal functions. SNR cells exert a tonic inhibitory influence on their target neurons, and this tonic inhibition is phasically interrupted by striatal activity leading to a transitory disinhibition of thalamic and brainstem neurons. As suggested by its spatial organization, the recurrent axonal network of SNR cells could contribute to improving the efficiency of this disinhibitory mechanism. First, by exerting lateral inhibitory interactions between adjacent neurons, the axon collateral network of SNR cells is expected to desynchronize the discharge of nigral cells that control the activity of the same population of target neurons, and in this way, it reinforces the tonic nature of the nigral influence. Second, after the discharge of a subset of striatal cells, the process of lateral inhibition through the recurrent collateral network likely contributes to enhance the contrast of activity be- 


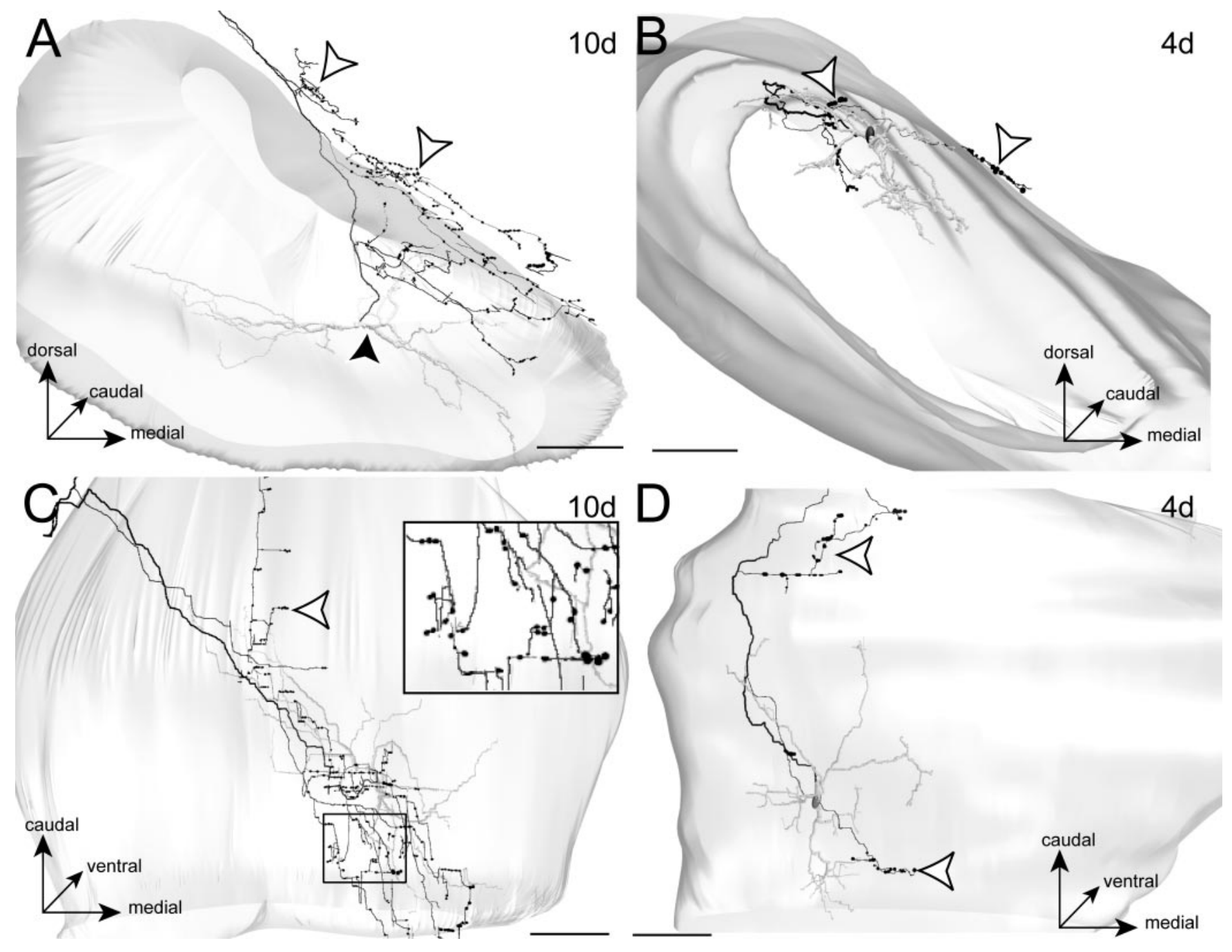

Figure 7. Spatial relationship between the axonal projections (open arrowheads) of single SNR cells in the SNC and the dendritic arborization of the parent neuron. Neurons $10 \mathrm{~d}(A, C)$ and $4 \mathrm{~d}(B$, $D)$ are illustrated. These neurons are examined from a rostral view in $A$ and $B$ and from a dorsal view in $C$ and $D$. The closed arrowhead in $A$ indicates the soma of the neuron. The inset in $C$ shows a higher magnification of the axonal terminal field in the SNC. Scale bars, $350 \mu \mathrm{m}$.

tween the nigral cells that receive a strong inhibitory input and those receiving a weak input. Indeed, when a subset of SNR cells is silenced by their striatal afferents, this will suppress the normal inhibitory influence of these nigral cells on their neighbors. This lateral disinhibitory process should contribute to focalizing the striatal influence on a restricted subpopulation of nigral neurons. Interestingly, the axonal collaterals of SNR cells have a preferential spatial distribution, because they are directed dorsally, laterally, and caudally. Considering that dendrites of neurons lying in a given nigral lamina extend ventrally and medially into adjacent laminas, it can be proposed that, by acting in the exactly opposite direction, the recurrent axonal network of SNR cells contribute to limiting the spread of striatal influence across the different functional laminas of SNR.

\section{Axonal projections to the SNC}

The existence of a reciprocal connection between the striatum and the dopaminergic neurons of the SNC has long been recognized. These connections form the basis of the so-called nigrostriatal loop circuit through which the striatum regulates its dopaminergic transmission (Glowinski et al., 1978; Wassef et al., 1981). In addition to this direct nigrostriatal loop circuit, extend- ing anatomical and physiological studies reported previously (Karabelas and Purpura, 1980; Deniau et al., 1982; Grofova et al., 1982; Grace and Bunney, 1985; Hajos and Greenfield, 1994; Tepper et al., 1995), the present observations stress the existence of an indirect circuit. In this indirect circuit, the GABAergic cells of the SNR act as an intermediate link between the striatum and the dopaminergic nigrostriatal neurons. Interestingly, these direct and indirect loop circuits are expected to have opposite effects on the activity of dopaminergic neurons. In addition to its direct inhibitory influence on nigrostriatal dopaminergic neurons, by inhibiting the tonically active GABAergic neurons of the SNR, the striatum can also exert an excitatory influence on dopaminergic neurons via a disinhibitory mechanism.

The open or closed character of the direct nigrostriatal loop circuit has long been debated, and clear evidence in favor of both components has been provided in rats and monkeys (Kitai et al., 1975; Nauta and Domesick, 1978; Lynd-Balta and Haber, 1994a,b; Maurin et al., 1999; Prensa and Parent, 2001). Recently, Haber et al. (2000) have proposed a spiral model of organization based on a divergent arrangement of the striatonigral connections. In this model, each striatal territory innervates at least two subpopulations of nigral neurons, one projecting back to the 

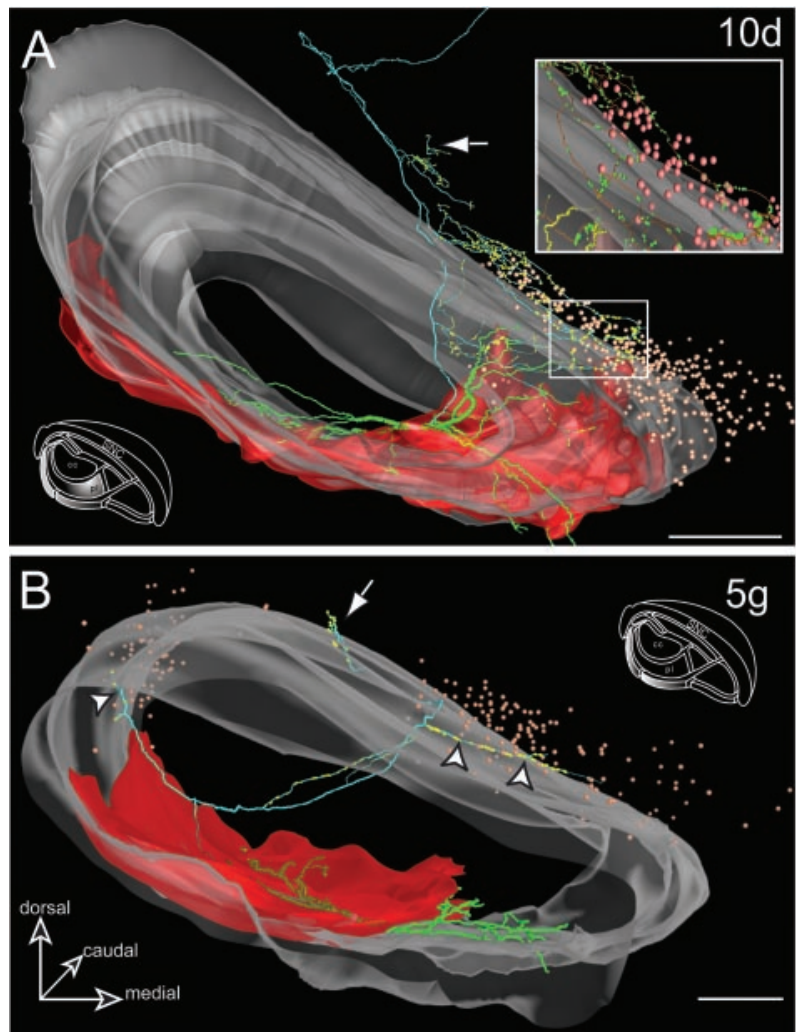

Figure 8. Spatial relationship between the axonal terminal field of single SNR cells, striatonigral projections, and nigrostriatal neurons. $A$, Rostral views of a $3 \mathrm{D}$ composite model incorporating the neuron $10 \mathrm{~d}$ lying in the projection field of the striatal sector related to the visualoculomotor cortical areas (inset, bottom left corner, filled area) and the nigrostriatal neurons innervating this striatal sector. The dendritic arborization is represented in green, the axon in blue, the axonal terminal boutons in yellow, the SNR in gray, the striatal projections in red, and the nigrostriatal neurons in pink. Note the presence of clusters of terminal boutons in register and out of register (arrow) with the population of nigrostriatal neurons. Inset, Top right corner, Higher magnification of the axonal boutons among nigrostriatal neurons. $B$, Rostral view of a 3D composite model incorporating the labeled neuron $5 \mathrm{~g}$ lying in the projection field of the striatal sector related to the visuocingulate cortical areas (inset, filled area) and the nigrostriatal neurons innervating this striatal sector. Note the presence of clusters of terminal boutons within (arrowheads) and outside (arrow) the population of nigrostriatal neurons. Color representation is the same as in $A$. Scale bars, $350 \mu \mathrm{m}$.

striatal site of origin and another innervating an adjacent striatal territory. The present observations show that the indirect nigrostriatal loop circuit displays a similar architecture. Indeed, the SNR cells lying in the projection field of a given functional striatal sector innervate not only the SNC region that projects to the striatal sector of origin but also SNC regions projecting to adjacent striatal sectors. Therefore, besides participating in a closed loop circuit through which striatal neurons activate their dopaminergic afferents by a disinhibitory process, the SNR may also contribute to the formation of open nigrostriatal loop circuits, allowing interactions between distinct striatal channels.

\section{References}

Alexander GE, Crutcher MD (1990) Functional architecture of basal ganglia circuits: neural substrates of parallel processing. Trends Neurosci 13:266-271.

Alexander GE, DeLong MR, Strick PL (1986) Parallel organization of functionally segregated circuits linking basal ganglia and cortex. Annu Rev Neurosci 9:357-381.

Berendse HW, Galis-de-Graaf Y, Groenewegen HJ (1992) Topographical organization and relationship with ventral striatal compartments of pre- frontal cortico-striatal projections in the rat. J Comp Neurol 316:314-347.

Bolam JP, Hanley JJ, Booth PA, Bevan MD (2000) Synaptic organization of the basal ganglia. J Anat 196:527-542.

Brown LL, Smith DM, Goldbloom LM (1998) Organizing principles of cortical integration in the rat neostriatum: corticostriate map of the body surface is an ordered lattice of curved laminae and radial points. J Comp Neurol 392:468-488

Bunney BS, Walters JR, Roth RH, Aghajanian GK (1973) Dopaminergic neurons: effect of antipsychotic drugs and amphetamine on single cell activity. J Pharmacol Exp Ther 185:560-571.

Chevalier G, Deniau JM (1990) Disinhibition as a basic process in the expression of striatal functions. Trends Neurosci 13:277-280.

Deniau JM, Chevalier G (1992) The lamellar organization of the rat substantia nigra pars reticulata: distribution of projection neurons. Neuroscience 46:361-377.

Deniau JM, Thierry AM (1997) Anatomical segregation of information processing in the rat substantia nigra pars reticulata. Adv Neurol 74:83-96.

Deniau JM, Hammond C, Riszk A, Feger J (1978) Electrophysiological properties of identified output neurons of the rat substantia nigra (pars compacta and pars reticulata): evidences for the existence of branched neurons. Exp Brain Res 32:409-422.

Deniau JM, Kitai ST, Donoghue JP, Grofova I (1982) Neuronal interactions in the substantia nigra pars reticulata through axon collaterals of the projection neurons: an electrophysiological and morphological study. Exp Brain Res 47:105-113.

Deniau JM, Menetrey A, Charpier S (1996) The lamellar organization of the rat substantia nigra pars reticulata: segregated patterns of striatal afferents and relationship to the topography of corticostriatal projections. Neuroscience 73:761-781.

Fallon JH, Moore RY (1978) Catecholamine innervation of the basal forebrain. IV. Topography of the dopamine projection to the basal forebrain and neostriatum. J Comp Neurol 180:545-580.

Fujimoto K, Kita H (1992) Responses of rat substantia nigra pars reticulata units to cortical stimulation. Neurosci Lett 142:105-109.

Glowinski J, Nieoullon A, Cheramy A (1978) Regulations of activity of the nigrostriatal dopaminergic systems. In: Neuronal information transfer (Karlin A, Tennyson V, Vogel HJ, eds), pp 35-45. New York: Academic.

Grace AA, Bunney BS (1985) Opposing effects of striatonigral feedback pathways on midbrain dopamine cell activity. Brain Res 333:271-284.

Groenewegen HJ, Wright CI, Beijer AV, Voom P (1999) Convergence and segregation of ventral striatal inputs and outputs. Ann NY Acad Sci 877:49-63.

Grofova I, Deniau JM, Kitai S (1982) Morphology of the substantia nigra pars reticulata projection neurons intracellularly labeled with HRP. J Comp Neurol 208:352-368.

Guyenet PG, Aghajanian GK (1978) Antidromic identification of dopaminergic and other output neurons of the rat substantia nigra. Brain Res 150:69-84.

Haber SN, Fudge JL, McFarland NR (2000) Striatonigrostriatal pathways in primates forms an ascending spiral from the shell to the dorsolateral striatum. J Neurosci 20:2369-2382.

Hajos M, Greenfield SA (1994) Synaptic connections between pars compacta and pars reticulata neurones: electrophysiological evidence for functional modules within the substantia nigra. Brain Res 660:216-224.

Hontanilla B, De Las Heras S, Gimenez-Amaya JM (1996) A topographic re-evaluation of the nigrostriatal projections to the caudate nucleus in the cat with multiple retrograde tracers. Neuroscience 72:485-503.

Juraska JM, Wilson CJ, Groves PM (1977) The substantia nigra of the rat: a Golgi study. J Comp Neurol 172:585-600.

Karabelas AG, Purpura DP (1980) Evidence for autapses in the substantia nigra. Brain Res 200:467-473.

Kincaid AE, Wilson CJ (1996) Corticostriatal innervation of the patch and matrix in the rat neostriatum. J Comp Neurol 374:578-592.

Kita H (1994) Physiology of two disynaptic pathways from the sensorimotor cortex to the basal ganglia output nuclei. In: The basal ganglia IV (Percheron G, McKenzie JS, Feger J, eds), pp 263-276. New York: Plenum.

Kitai ST, Wagner A, Ono T (1975) Nigro-caudate and caudato-nigral relationship: an electrophysiological study. Brain Res 85:44-48.

Kitano H, Tanibushi I, Jinnai K (1998) The distribution of neurons in the 
substantia nigra pars reticulata with input from the motor, premotor and prefrontal areas of the cerebral cortex in monkeys. Brain Res 784:228-238.

Lynd-Balta E, Haber SN (1994a) The organization of midbrain projections to the ventral striatum in the primate. Neuroscience 59:609-623.

Lynd-Balta E, Haber SN (1994b) The organization of midbrain projections to the striatum in the primate: sensorimotor-related striatum versus ventral striatum. Neuroscience 59:625-640.

Mailly P, Charpier S, Mahon S, Menetrey S, Thierry AM, Glowinski J, Deniau JM (2001) Dendritic arborizations of the rat substantia nigra pars reticulata neurons: spatial organization and relation to the lamellar compartmentation of striato-nigral projections. J Neurosci 21:6874-6888.

Maurice N, Deniau JM, Glowinski J, Thierry AM (1999) Relationships between the prefrontal cortex and the basal ganglia in the rat: physiology of the cortico-nigral circuits. J Neurosci 19:4674-4681.

Maurin Y, Banrezes B, Menetrey A, Mailly P, Deniau JM (1999) Threedimensional distribution of nigrostriatal neurons in the rat: relation to the topography of striatonigral projections. Neuroscience 91:891-909.

McGeorge AJ, Faull RL (1989) The organization of the projection from the cerebral cortex to the striatum in the rat. Neuroscience 29:503-537.

Middleton FA, Strick PL (1996) The temporal lobe is a target of output from the basal ganglia. Proc Natl Acad Sci USA 93:8683-8687.

Middleton FA, Strick PL (2002) Basal ganglia "projections" to the prefrontal cortex of the primate. Cereb. Cortex 12:926-935.

Mink JW, Thach WT (1993) Basal ganglia intrinsic circuits and their role in behavior. Curr Opin Neurobiol 3:950-957.

Nauta WJH, Domesick VB (1978) Crossroads of limbic and striatal circuitry: hypothalamic-nigral connections. In: Limbic mechanisms (Livingstone KE, Hornykiewicz O, eds), pp 75-93. New York: Plenum.

Neafsey EJ, Bold EL, Haas G, Hurley-Gius KM, Quirk G, Sievert CF, Terreberry RR (1986) The organization of the rat motor cortex: a microstimulation mapping study. Brain Res 396:77-96.

Parent A (1990) Extrinsic connections of the basal ganglia. Trends Neurosci 13:254-258.

Paxinos G, Watson C (1986) The rat brain in stereotaxic coordinates, Ed 2. New York: Academic.
Percheron G, Filion M (1991) Parallel processing in the basal ganglia: up to a point. Trends Neurosci 14:55-59.

Pinault D (1996) A novel single-cell staining procedure performed in vivo under electrophysiological control: morpho-functional features of juxtacellularly labeled thalamic cells and other central neurons with biocytin or Neurobiotin. J Neurosci Methods 65:113-136.

Prensa L, Parent A (2001) The nigrostriatal pathway in the rat: a single-axon study of the relationship between dorsal and ventral tier nigral neurons and the striosome/matrix striatal compartments. J Neurosci 21:7247-7260.

Ryan LJ, Clark KB (1991) The role of the subthalamic nucleus in the response of globus pallidus neurons to stimulation of the prelimbic and agranular frontal cortices in rats. Exp Brain Res 86:641-651.

Sakai ST, Grofova I, Bruce K (1998) Nigrothalamic projections and nigrothalamocortical pathway to the medial agranular cortex in the rat: single and double labeling light and electron microscopic studies. J Comp Neurol 391:506-525.

Smith Y, Shink E, Sidibe M (1998) Neuronal circuitry and synaptic connectivity of the basal ganglia. Neurosurg Clin N Am 9:203-222.

Szabó J (1980) Distribution of striatal afferents from the mesencephalon in the cat. Brain Res 188:3-21.

Tepper JM, Martin LP, Anderson DR (1995) GABA A $_{\mathrm{A}}$ receptor-mediated inhibition of rat substantia nigra dopaminergic neurons by pars reticulata projection neurons. J Neurosci 15:3092-3103.

Veening JG, Cornelissen FM, Lieven PA (1980) The topical organization of the afferents to the caudatoputamen of the rat: a horseradish peroxidase study. Neuroscience 5:1253-1268.

Wassef M, Berod A, Sotelo C (1981) Dopaminergic dendrites in the pars reticulata of the rat substantia nigra and their striatal input: combined immunocytochemical localization of tyrosine hydroxylase and anterograde degeneration. Neuroscience 6:2125-2139.

Webster KE (1961) Cortico-striate interrelations in the albino rat. J Anat 95:532-544.

Wurtz RH, Hikosaka O (1986) Role of the basal ganglia in the initiation of saccadic eye movements. Prog Brain Res 64:175-190.

Yeterian EH, Van Hoesen GW (1978) Cortico-striate projections in the rhesus monkey: the organization of certain cortico-caudate connections. Brain Res 139:43-63. 